JPE 11-5-14

\title{
Combined Design of PSS and STATCOM Controllers for Power System Stability Enhancement
}

\author{
Ahmad Rohani ${ }^{\dagger}$, M. Reza Safari Tirtashi*, and Reza Noroozian** \\ $\dagger$ Young Researchers Club, Shiraz Branch, Islamic Azad University, Shiraz, Iran \\ * Young Researchers Club, Behshahr Branch, Islamic Azad University, Behshahr, Iran \\ ** Dept. of Electrical Engineering, University of Zanjan, Zanjan, Iran
}

\begin{abstract}
In this paper a robust method is presented for the combined design of STATCOM and Power System Stabilizer (PSS) controllers in order to enhance the damping of the low frequency oscillations in power systems. The combined design problems among PSS and STATCOM internal ac and dc voltage controllers has been taken into consideration. The equations that describe the proposed system have been linearized and a Fuzzy Logic Controller (FLC) has been designed for the PSS. Then, the Particle Swarm Optimization technique (PSO) which has a strong ability to find the most optimistic results is employed to search for the optimal STATCOM controller parameters. The proposed controllers are evaluated on a single machine infinite bus power system with the STATCOM installed in the midpoint of the transmission line. The results analysis reveals that the combined design has an excellent capability in damping a power system's low frequency oscillations, and that it greatly enhances the dynamic stability of power systems. Moreover, a system performance analysis under different operating conditions and some performance indices studies show the effectiveness of the combined design.
\end{abstract}

Key Words: Combined design, Fuzzy logic controller, Particle swarm optimization, STATCOM

\section{INTRODUCTION}

Flexible AC Transmission Systems (FACTS) utilize high power semiconductor devices to control the reactive power flow and thus the active power flow of transmission systems so that the ac power can be transmitted across long distances efficiently [1]. The conception of FACTS as a total network control philosophy was first introduced in 1988 by N.G. Hingorani [2] from the Electric Power Research Institute (EPRI) in the USA, although power electronic controlled devices had been used in transmission networks for many years before that. Some of the FACTS devices include the STATic synchronous COMpensator (STATCOM), Static Var Compensator (SVC), Unified Power Flow Controller (UPFC), Inter-phase Power Flow Controller (IPFC), Static Synchronous Series Controller (SSSC), Convertible Series Compensator (CSC), Thyristor Controlled Series Compensator (TCSC), Thyristor Controlled Phase Shifting Transformer (TCPST), and Super Conducting Magnetic Energy Storage (SMES). The devices may be connected so as to provide either series compensation or shunt

\footnotetext{
Manuscript received Oct. 4, 2011; revised May 8, 2011

Recommended for publication by Associate Editor Se-Kyo Chung.

$\dagger$ Corresponding Author: rohania63@gmail.com

Tel: +98-711-8423233, Islamic Azad University, Shiraz Branch, Iran

* Young Researchers Club, Islamic Azad University, Behshahr Branch, Iran

** Dept. of Electrical Engineering, University of Zanjan, Iran
}

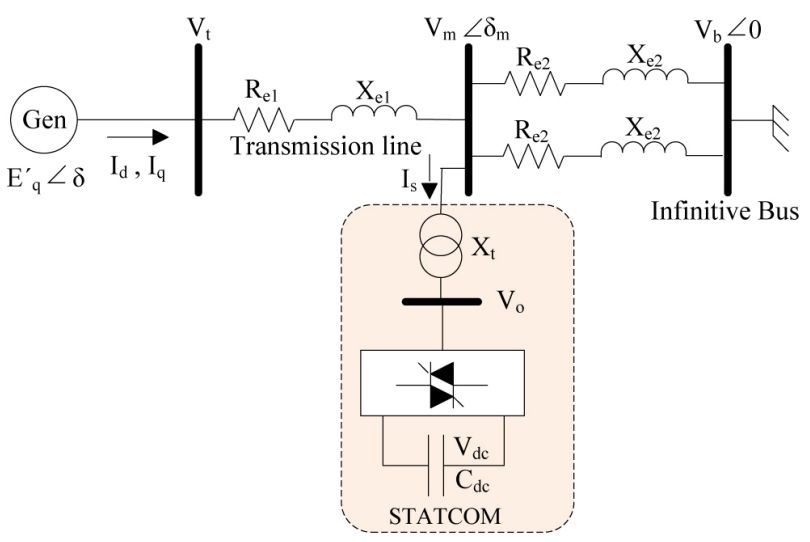

Fig. 1. SMIB system model with a STATCOM.

compensation depending upon their compensating strategies. It has been proved that shunt FACTS devices give maximum benefit due to their stabilized voltage support when sited at the mid-point of the transmission line [3].

The STATCOM is a promising technology being extensively used as a state-of-the-art dynamic shunt compensator for reactive power control in transmission and distribution systems [4]. Therefore it has been acknowledged as the nextgeneration reactive power controller in power systems [5]. Various techniques for evaluating system damping in the 


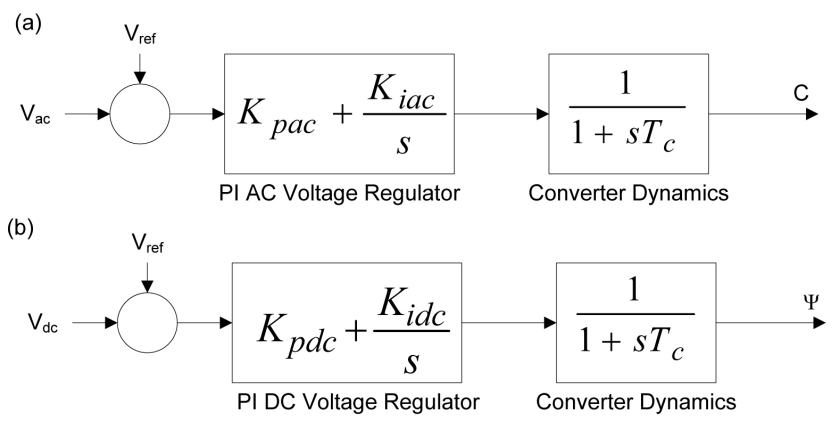

Fig. 2. STATCOM PI controller for (a) ac voltage and. (b) dc voltage.

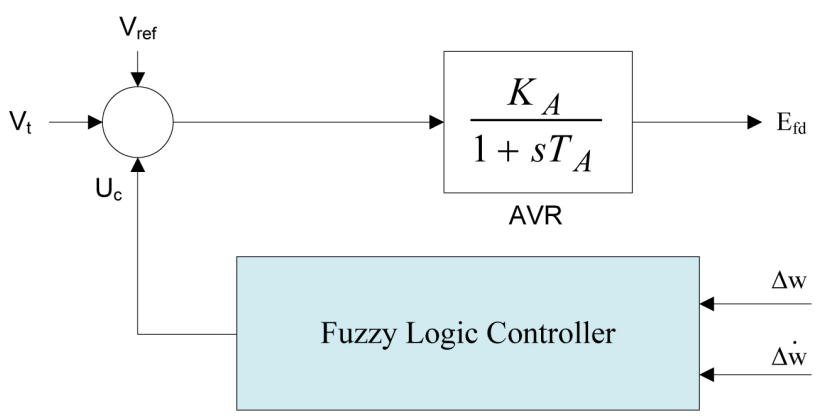

Fig. 3. Model of generator AVR and PSS control system with FLC.

presence of a STATCOM are reported in the literature [6][13]. Most of the above mentioned techniques describe the controller design for damping improvement. In Ref. [6] a multivariable feedback linearization scheme for STATCOM control has been preformed. Also a STATCOM voltage controller has been designed using the loop-shaping technique [7]. The interactions and multivariable design of STATCOM ac and dc voltage control has been reported in [8]. While most of the control designs are carried out with linearized models, nonlinear control strategies for a STATCOM have also been reported recently [14]-[16].

The Power System Stabilizer (PSS) is still used as an effective and economical facility to tackle this problem [17]. Reference [18] shows that the appropriate selection of PSS parameters can achieve satisfactory performance during system upsets.

Intelligent techniques have been used to design controllers for power systems both with and without a STATCOM. Recently, Particle Swarm Optimization (PSO) appeared as a promising evolutionary technique for handling optimization problems [19], [20]. On the other hand, the Fuzzy Logic Controller (FLC) [21] provides a model free approach for PSS and STATCOM controllers and can be effective over the entire range of power system operations. Applications of FLCs have also been reported in [22]-[24]. However, uncoordinated control of FACTS devices and PSSs may cause destabilizing interactions. To improve overall system performance, many studies were conducted on the coordination between PSSs and FACTS damping controllers [25]-[30].

This article investigates the stability enhancement problem of power systems considering the combined design of PSS and STATCOM controllers. A FLC has been designed for the PSS. Then, PSO is employed to search for optimal STATCOM controller parameters. The remainder of the paper is organized as follows. Section II describes the modeling of the proposed system and STATCOMs connected to the distribution system. The power system linearized model is presented in Section III. A brief overview of the proposed FLC and PSO are provided in Section IV and V, respectively. The computer simulation results for the system under study are presented and discussed in Section VI. Finally, Section VII concludes this paper.

\section{Model of Proposed System}

\section{A. Generator and Exciter}

A synchronous machine with an IEEE type-ST1 excitation system connected to an infinite bus through a transmission line has been selected to demonstrate the derivation of simplified linear models of power systems for dynamic stability analysis. The single machine infinite bus (SMIB) power system shown in Fig. 1 comprises a synchronous generator connected to an infinite bus through a transmission line. The STATCOM is located in the middle of the transmission line. The transmission line has an impedance of $Z=R_{e}+j X_{e}$ for both sections.

The equations that describe the generator and the excitation system have been represented in the following equations:

$$
\begin{gathered}
\dot{\delta}=\omega_{b}(\omega-1) \\
\dot{\omega}=\frac{P_{m}-P_{e}-D(\omega-1)}{M}
\end{gathered}
$$

where $P_{m}$ and $P_{e}$ are the input and output powers of the generator, respectively; $M$ and $D$ are the inertia constant and the damping coefficient, respectively; $\omega_{b}$ is the synchronous speed; and $\delta$ and $\omega$ are the rotor angle and speed, respectively. The output power of the generator can be expressed in terms of the $d$-and $q$-axis components of the armature current, $i$, and terminal voltage, $v_{t}$, can be expressed as:

$$
P_{e}=V_{t d} I_{d}+V_{t q} I_{q}
$$

The internal voltage, $E^{\prime}$ q, equation is

$$
\dot{E}_{q}^{\prime}=\frac{E_{f d}-\left(\mathrm{X}_{d}-X_{d}^{\prime}\right) i d-E_{q}^{\prime}}{T^{\prime} d o}
$$

Where $E_{f d}$ is the field voltage; $T^{\prime}{ }_{d o}$ is the open circuit field time constant; and $X_{d}$ and $X^{\prime}{ }_{d}$ are the $d$-axis reactance and the $d$-axis transient reactance of the generator, respectively.

The excitation System can be expressed as:

$$
\dot{E}_{f d}=\frac{k_{A}\left(V_{r e f}-V_{t}+U_{P S S}\right)-E_{f d}}{T_{A}}
$$

where $k_{A}$ and $T_{A}$ are the gain and time constant of the excitation system, respectively; and $V_{r e f}$ is the reference voltage. The terminal voltage, $V_{t}$, can be expressed as:

$$
\begin{gathered}
V_{t}=V_{t d}+j V_{t q} \\
V_{t d}=X_{q} I_{q} \\
V_{t q}=E_{q}^{\prime}-X_{d}^{\prime} \mathrm{I}_{d}
\end{gathered}
$$

where $X \mathrm{q}$ is the q-axis reactance of the generator. 


\section{B. STATCOM-Based Stabilizer}

The STATCOM is represented by a first order differential equation relating the STATCOM DC capacitor voltage and the current. As shown in Fig. 1, the STATCOM consists of a stepdown transformer with a leakage reactance of $X_{t}$, a three phase gate turn-off (GTO)-based voltage source converter (VSC) and a dc capacitor. The STATCOM model used in this study is found to be good enough for the low frequency oscillation stability problem [14]. The VSC generates a controllable ac voltage $V_{o}$ given by:

$$
V_{o}=C V_{d c} \angle \psi
$$

where $C=m k, m$ is the modulation ratio defined by pulse width modulation (PWM), $k$ is the ratio between the ac and dc voltage depending on the converter structure, $V_{d c}$ is the dc voltage, and $\Psi$ is the phase defined by PWM. The magnitude and the phase of $V_{o}$ can be controlled through $m$ and $\Psi$, respectively. By adjusting the STATCOM ac voltage $V_{o}$, the active and reactive power exchange between the STATCOM and the power system can be controlled through the difference between $V_{o}$ and the STATCOM-bus voltage $V_{m}$. The $\mathrm{dc}$ voltage $V_{d c}$ is governed by:

$$
\dot{V}_{d c}=\frac{I_{d c}}{C_{d c}}=\frac{C}{C_{d c}}\left(I_{s d} \cos \psi+I_{s q} \sin \psi\right)
$$

where $C_{d c}$ is the dc capacitor value and $I_{d c}$ is the capacitor current while $i_{s d}$ and $i_{s q}$ are the $d$ - and $q$-components of the STATCOM current $I_{s}$, respectively. The $d$ - and $q$-axis components of the $I_{d}$ can be expressed as:

$$
\begin{gathered}
I_{d}=\frac{c_{1} E_{q}^{\prime}-c_{2} C V_{d c} \sin \psi-v_{b} \cos \delta}{c_{1} \mathrm{X}_{d}^{\prime}+c_{3}} \\
I_{q}=\frac{c_{2} C V_{d c} \cos \psi+v_{b} \sin \delta}{c_{1} \mathrm{X}_{q}+c_{3}}
\end{gathered}
$$

where $c_{1}, c_{2}$, and $c_{3}$ are constants. Fig. 2 illustrates a block diagram of a STATCOM ac and dc voltage PI controller. The proportional and integral gains are $K_{p a c}, K_{i a c}$ and $K_{p d c}, K_{i d c}$ for ac and dc voltages, respectively. The excitation system of the generator consists of a simple AVR along with a supplementary PSS. The complete AVR and PSS control system with the FLC used in this paper is shown in Fig. 3.

\section{LINEARIZED MODEL}

A linear dynamic model is obtained by linearizing the nonlinear model round an operating condition $\left(P_{e}=0.8, Q_{e}\right.$ $=0.28)$. The linearized model of the proposed power system is given as follows:

$$
\begin{gathered}
\Delta \dot{\delta}=\omega_{b} \Delta \omega \\
\Delta \dot{\omega}=\frac{\Delta P_{m}-\Delta P_{e}-D \Delta \omega}{\mathrm{M}} \\
\Delta \dot{E}_{q}^{\prime}=\frac{\Delta E_{f d}-\left(\mathrm{X}_{d}-\mathrm{X}_{d}^{\prime}\right) \Delta I_{d}-\Delta \mathrm{E}_{q}^{\prime}}{T_{d o}^{\prime}} \\
\Delta \dot{E}_{f d}=\frac{k_{A}\left(\Delta V_{r e f}-\Delta V_{t}+U_{P S S}\right)-\Delta E_{f d}}{T_{A}}
\end{gathered}
$$
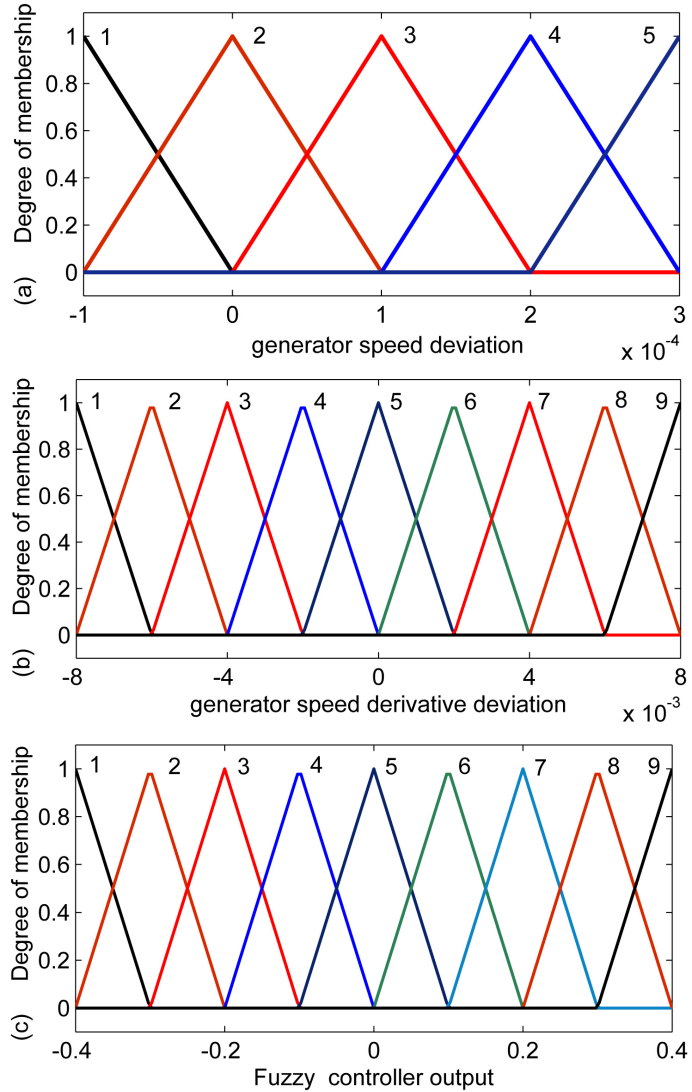

Fig. 4. Membership functions of inputs and output.

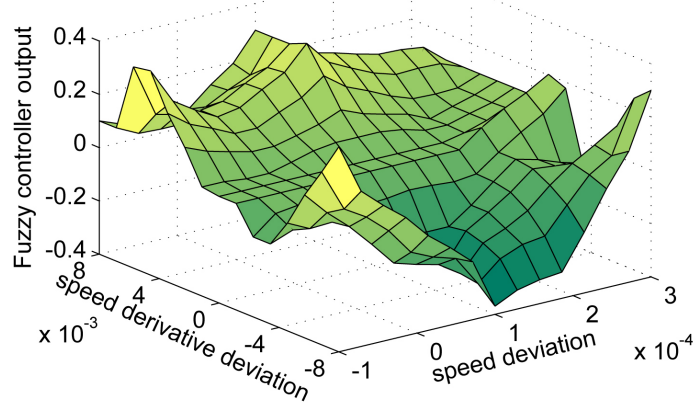

Fig. 5. Decision surface of proposed FLC.

$$
\begin{aligned}
\Delta P_{e}= & k_{p \delta} \Delta \delta+k_{p e q} \Delta E_{q}^{\prime}+k_{p d c} \Delta V_{d c} \\
& +k_{p c} \Delta c+k_{p \psi} \Delta \psi \\
\Delta V_{t}= & k_{v \delta} \Delta \delta+k_{v e q} \Delta E_{q}^{\prime}+k_{v d c} \Delta V_{d c} \\
& +k_{v c} \Delta c+k_{v \psi} \Delta \psi \\
\Delta I_{d}= & k_{i \delta} \Delta \delta+k_{i e q} \Delta E_{q}^{\prime}+k_{i d c} \Delta V_{d c} \\
& +k_{i c} \Delta c+k_{i \psi} \Delta \psi \\
\Delta I_{q}= & k_{q \delta} \Delta \delta+k_{q e q} \Delta E_{q}^{\prime}+k_{q d c} \Delta V_{d c} \\
& +k_{q c} \Delta c+k_{q \psi} \Delta \psi \\
\Delta V= & k_{d \delta} \Delta \delta+k_{d e q} \Delta E_{q}^{\prime}+k_{d d c} \Delta V_{d c} \\
& +k_{d c} \Delta c+k_{d \psi} \Delta \psi \\
\Delta V_{a c}= & k_{a \delta} \Delta \delta+k_{a e q} \Delta E_{q}^{\prime}+k_{a d c} \Delta V_{d c} \\
& +k_{a c} \Delta c+k_{a \psi} \Delta \psi
\end{aligned}
$$

where $k_{p \delta}, k_{p e q}, k_{p d c}, k_{p c}, k_{p \psi}, k_{v \delta}, k_{v e q}, k_{v d c}, k_{v c}, k_{v \psi}, k_{i \delta}$, $k_{i e q}, k_{i d c}, k_{i c}, k_{i \psi}, k_{q \delta}, k_{q e q}, k_{q d c}, k_{q c}, k_{q \psi}, k_{d \delta}, k_{d e q}, k_{d d c}$, 


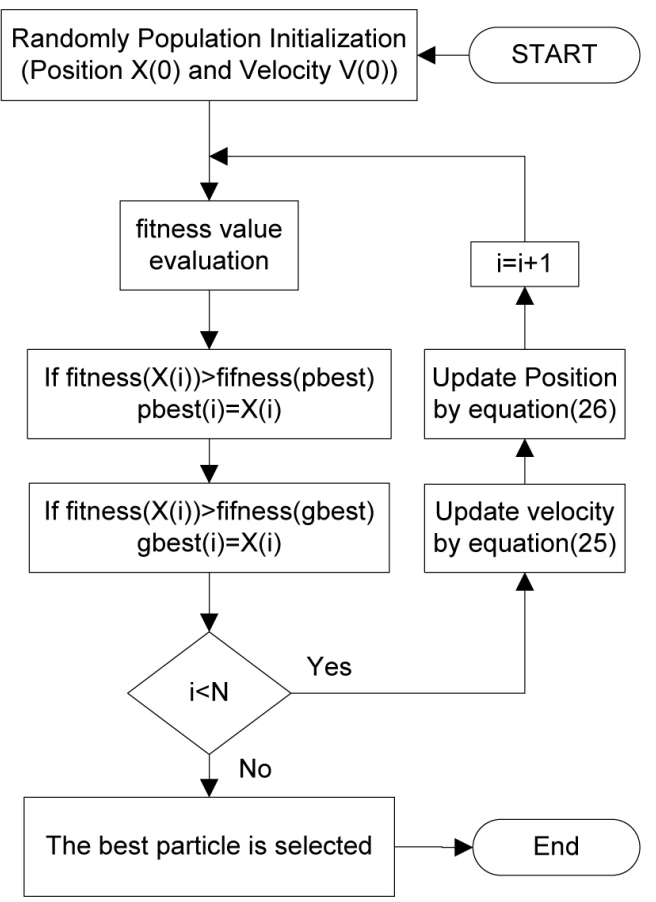

Fig. 6. PSO flow chart.

$k_{d c}, k_{d \psi}, k_{a \delta}, k_{a e q}, k_{a d c}, k_{a c}$, and $k_{a \psi}$ are linearization constants. The above linearizing procedure yields the following linearized power system model:

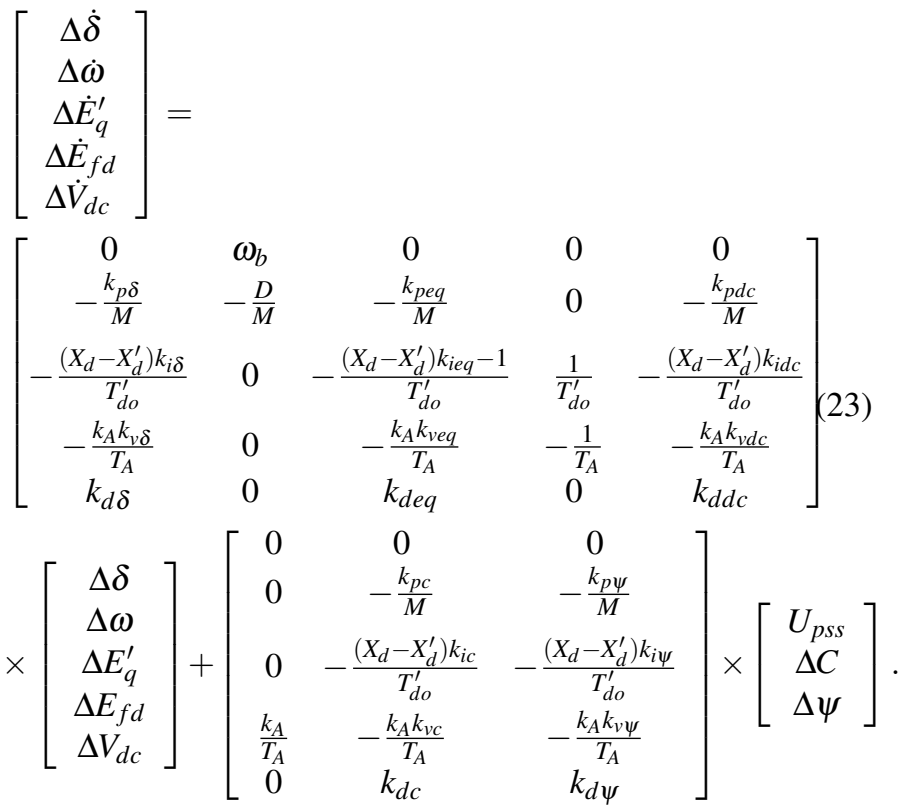

In short

$$
\dot{X}=A X+B U
$$

where the state vector $X$ is $\left[\Delta \delta, \Delta \omega, \Delta E_{q}^{\prime}, \Delta E_{f d}, \Delta V_{d c}\right]^{T}$ and the control vector $U$ is $\left[U_{p s s}, \Delta C, \Delta \Psi\right]^{T}[10]$.

\section{FuZZY LOGIC}

In 1965, Zadeh proposed fuzzy logic, and it has been effectively utilized in many field of knowledge to solve control and optimization problems [24]. The FLC is a good means to control the parameters when there is not any direct or exact

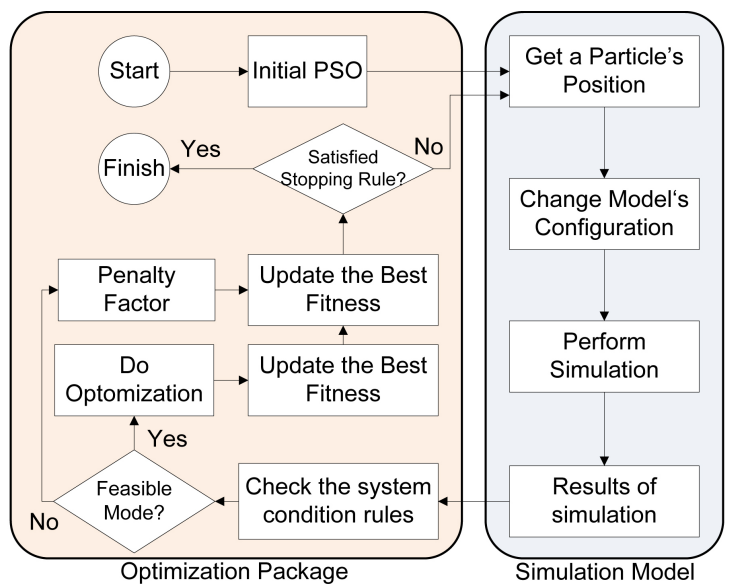

Fig. 7. Optimization method on stochastic simulation.

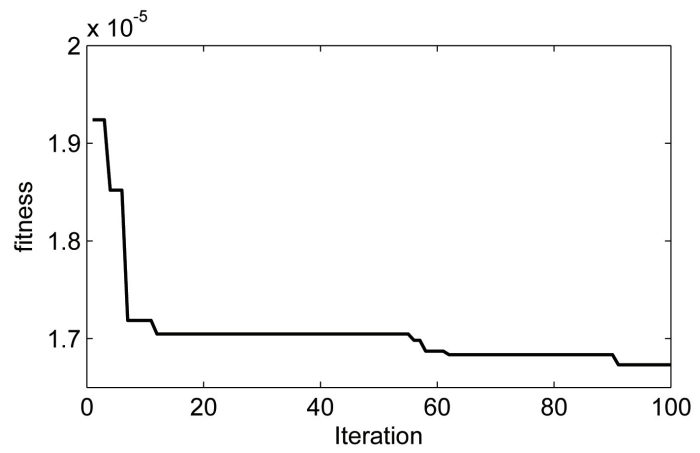

Fig. 8. Convergence of PSO.

relation between the input and the output of a system, and we only have some linguistic relations in the If-Then form [31]. The use of fuzzy logic has received increased attention in recent years because of its usefulness in reducing the need for complex mathematical models in problem solving [32]. In the power system area, it has been used in stability studies, load frequency control, unit commitment, reactive compensation in distribution networks and other areas. A fuzzy control system is made from different blocks such as the numeral quantity converter to fuzzy quantities (fuzzifier interface) block, the fuzzy logical decision maker section, the knowledge base section, and the defuzzier interface block.

The following steps are involved in designing a fuzzy PSS controller [33]:

1) Choose the inputs to the FLC. As shown in Fig. 3, only two inputs, the generator speed deviation $(\Delta \omega)$ and the generator speed derivative deviation $(\Delta \hat{\omega})$, have been employed in this study. The symbol $U_{c}$ has been synonymously used to represent the output or decision variable of the FLC.

2) Choose membership functions to represent the inputs in fuzzy set notation. Triangular functions are chosen in this study. Fuzzy representations of the generator speed change, acceleration, and output variable have been illustrated in Fig. 4.

3) A set of decision rules relating the inputs to the output are compiled and stored in the memory in the form of a "decision surface". The decision surface is provided in Fig. 5. 


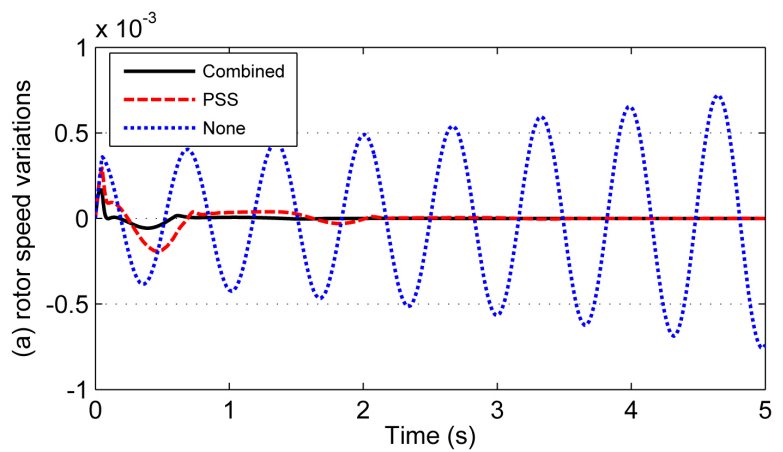

(a)

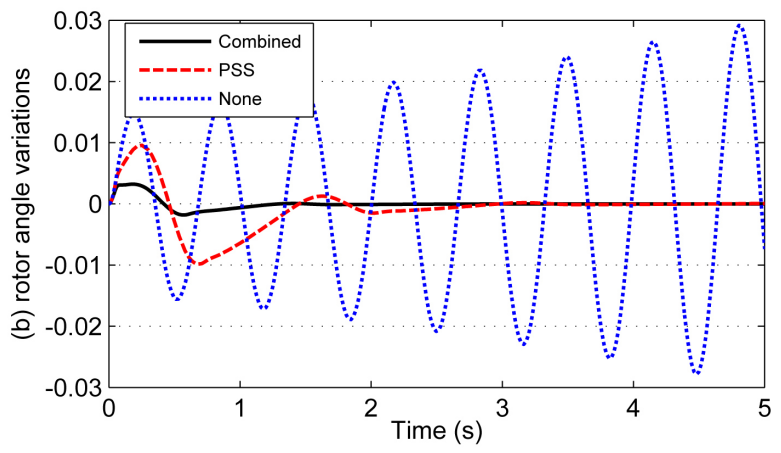

(b)

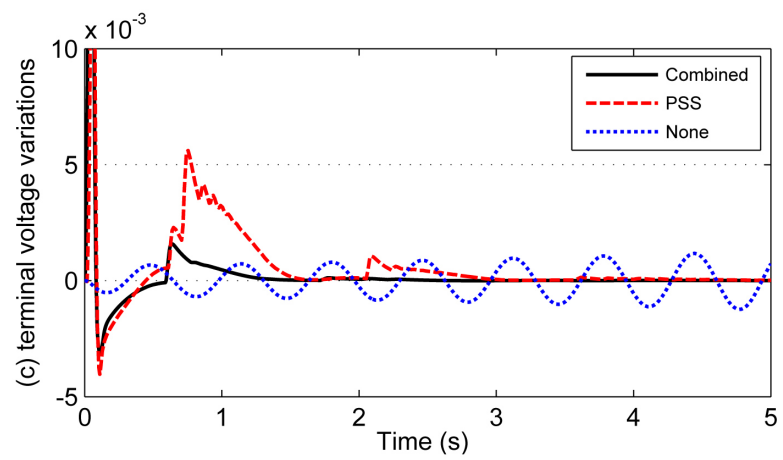

(c)

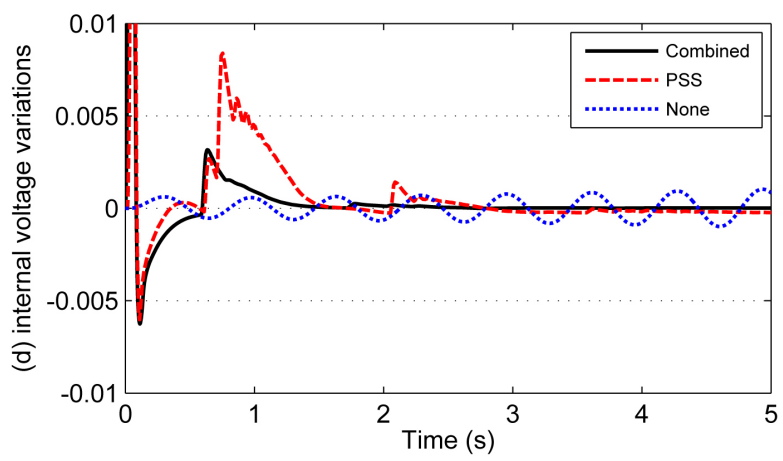

(d)

Fig. 9. Comparison of transient response for a three-cycle fault disturbance with combined controllers, without STATCOM, and without FLC-PSS. (a) Rotor speed variations. (b) Rotor angle variations. (c) Terminal voltage variations, and (d) Internal voltage variations.

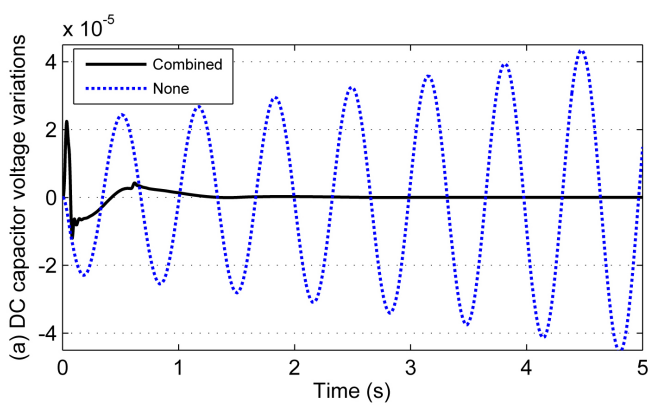

(a)

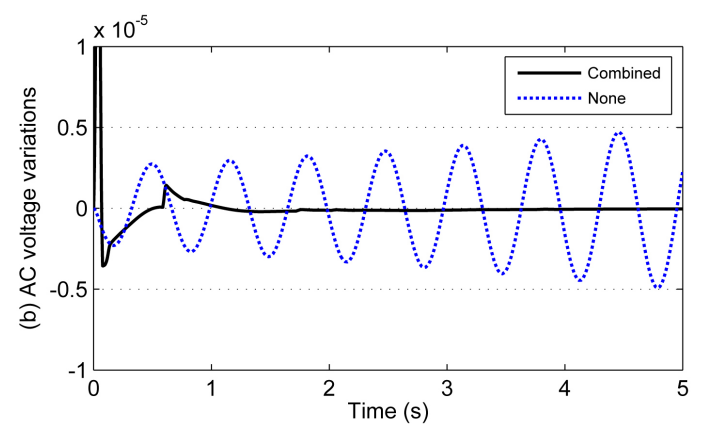

(b)

Fig. 10. Comparison of transient response for a three-cycle fault disturbance with combined controllers and without FLC-PSS. (a) DC capacitor voltage variations and (b) $\mathrm{AC}$ voltage variations.

\section{PSO ALGORITHM}

PSO is a population based stochastic optimization technique developed by Eberhart and Kennedy in 1995 [34]. The PSO algorithm is inspired by the social behavior of bird flocking or fish schooling.

The standard PSO algorithm employs a population of particles. The particles fly through the $\mathrm{n}$-dimensional domain space of the function to be optimized (in this paper, minimization is assumed). The state of each particle is represented by its position $x_{i}=\left(x_{i 1}, x_{i 2}, \ldots, x_{i n}\right)$ and velocity $v_{i}=\left(v_{i 1}, v_{i 2}, \ldots, v_{i n}\right.$ ), and the states of the particles are updated. The flow chart of the procedure is shown in Fig. 6.

During every iteration, each particle is updated by following two "best" values. The first one is the position vector of the best fitness this particle has achieved so far. The fitness value $p_{i}=\left(p_{i 1}, p_{i 2}, \ldots, p_{i n}\right)$ is also stored. This position is called pbest. The other "best" position that is tracked by the particle swarm optimizer is the best position, obtained so far, by any particle in the population. This best position is the current global best $p_{g}=\left(p_{g 1}, p_{g 2}, \ldots, p_{g n}\right)$ and is called gbest. At each time step, after finding the two best values, the particle updates its velocity and position according to (25) and (26), respectively.

$$
\begin{aligned}
v_{i(k+1)}= & \omega \times v_{i k}+c_{1} \times r_{1}\left(\text { pbest }_{i}-x_{i k}\right) \\
& +c_{2} \times r_{2}\left(\text { gbest }_{k}-x_{i k}\right) \\
& x_{i(k+1)}=x_{i k}+v_{i(k+1)}
\end{aligned}
$$

where $v_{i k+1}$ is the velocity of particle number $(i)$ at the $(k+l)^{t h}$ iteration, $x_{i k}$ is the current particle (solution or position), $r_{1}$ and $r_{2}$ are random numbers between $O$ and $1, c_{1}$ is the self confidence (cognitive) factor and $c_{2}$ is the swarm confidence 
TABLE I

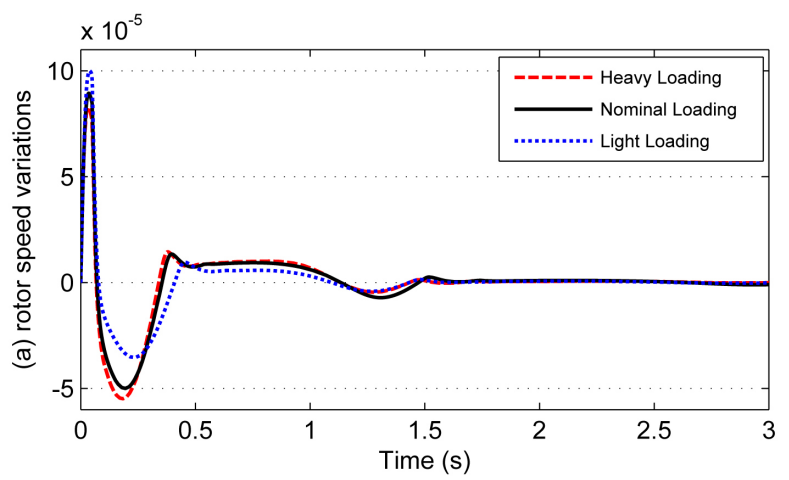

(a)

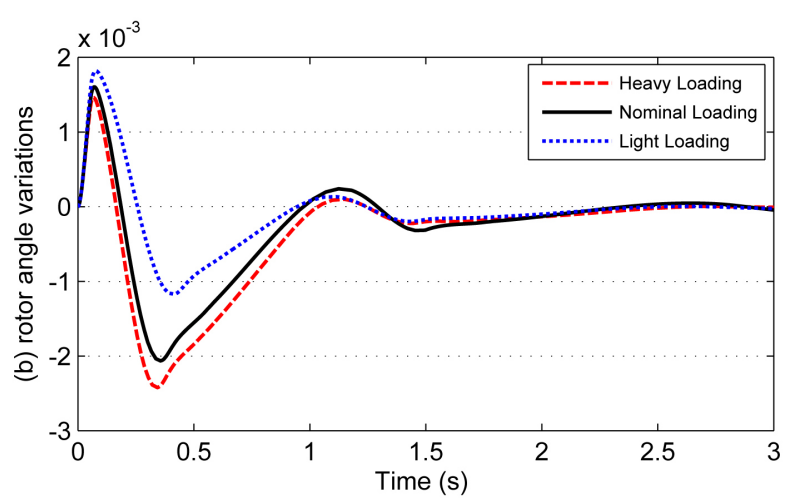

(b)

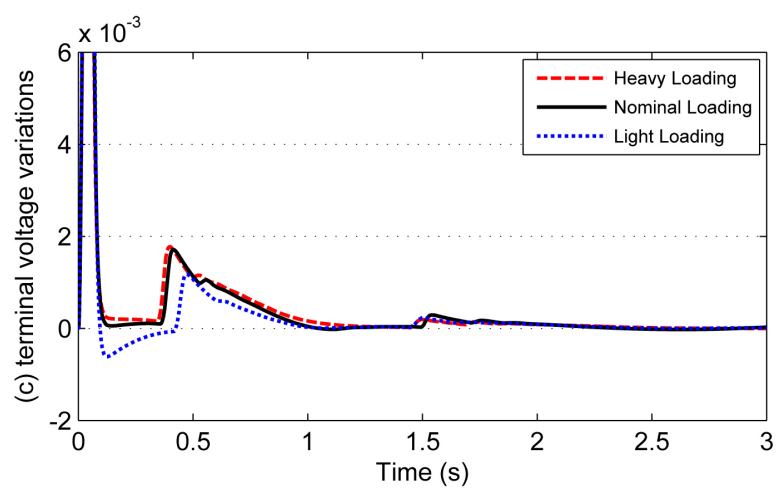

(c)

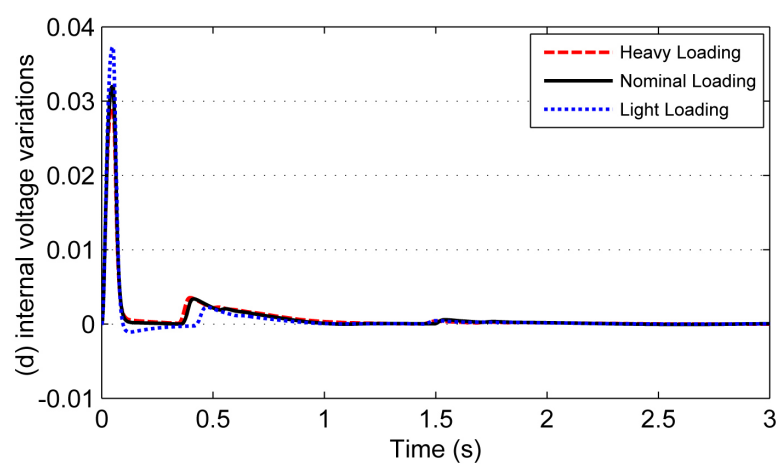

(d)

Fig. 11. System transient response for a three-cycles fault disturbance with nominal, light, and heavy loading in combined control scheme. (a) rotor speed variations, (b) rotor angle variations, (c) terminal voltage variations, and (d) internal voltage variations.
Optimized Parameters Setting in Combined Design

\begin{tabular}{|l|l|l|l|}
\hline \multicolumn{2}{|l|}{ DC PI controller } & \multicolumn{2}{|l|}{ AC PI controller } \\
\hline$K_{p d c}$ & -678.01 & $K_{p a c}$ & 440.15 \\
\hline$K_{i d c}$ & -926.71 & $K_{i a c}$ & 27.3 \\
\hline
\end{tabular}

(social) factor. Usually $c_{1}$ and $c_{2}$ are in the range from 1.5 to 2.5 and $\omega$ is the inertia factor that takes values downward from 1 to $O$ according to the iteration number. When a predetermined termination condition is reached, $p_{g}$ is returned as the optimal value found.

\section{Simulation Results}

In this study, the performance of the combined controllers for the stabilization of a synchronous generator is evaluated by computer simulation studies. The FLC has designed for the PSS. Then, PSO was employed to search for the optimal STATCOM controller parameters. The multi-objective function that was used to combine the internal ac and dc PI controllers is demonstrated in (27), where $t_{\text {sim }}$ is the simulation time, $d w$ is the generator speed deviation, $d v_{d c}$ is the dc voltage deviation, and $d v_{a c}$ is the STATCOM-bus ac voltage deviation.

$$
\text { fitness }=\int_{0}^{t_{s i m}} t \times\left[|d w|+\mu_{1}\left|d v_{d c}\right|+\mu_{2}\left|d v_{a c}\right|\right] d t
$$

where $\mu_{1}$ and $\mu_{2}$ are the weighting factors. While the internal PI controllers are designed to minimize the variations in ac and dc voltages of the STATCOM, $K_{p d c}, K_{i d c}, K_{p a c}$, and $K_{i a c}$ are the STATCOM PI controller parameters as shown in Fig. 2. Therefore, the design problem can be formulated as the following optimization problem:

Minimize fitness

Subject to:

$$
\begin{gathered}
K_{p d c}^{\min } \leq K_{p d c} \leq K_{p d c}^{\max } \\
K_{i d c}^{\min } \leq K_{i d c} \leq K_{i d c}^{\max } \\
K_{p a c}^{\min } \leq K_{p a c} \leq K_{p a c}^{\max } \\
K_{i a c}^{\min } \leq K_{i a c} \leq K_{i a c}^{\max } .
\end{gathered}
$$

Fig. 7 shows the overall PSO method and how it interplays with the simulation model during optimization. Fig. 8 depicts the convergence of the optimization of the algorithms. The optimized parameters are presented in table I. Optimized parameters have been earned when the input power of the generator has been changed $3 \%$ for a three-cycle disturbance in the mechanical generator power input and the normal operating condition.

In this study, the SMIB system was tested and compared with various configurations. The system data is given in appendix A. The STATCOM's internal ac and dc PI voltage controllers are designed in combination with the PSS controller which includes a FLC as discussed in the following cases:

Case 1. A STATCOM controller combined with a PSS.

Case 2. Only a PSS including a FLC.

Case 3. Without considering a FLC on a PSS.

The transient performance of the rotor speed variations, rotor angle variations, terminal voltage variations, and internal 


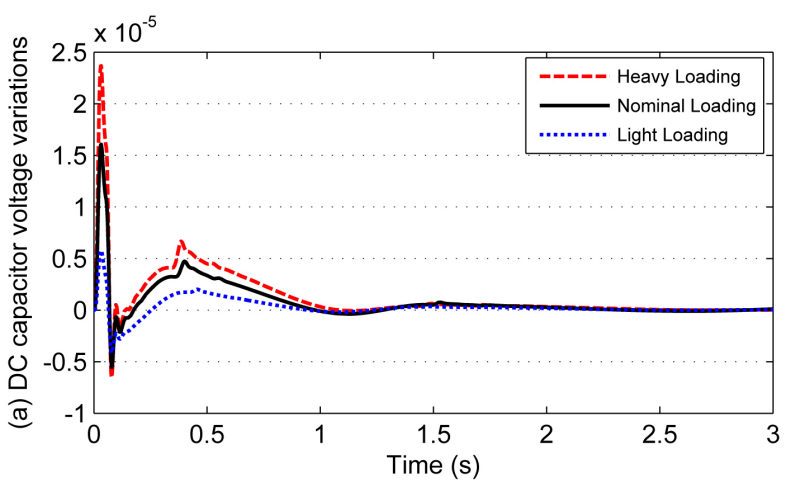

(a)

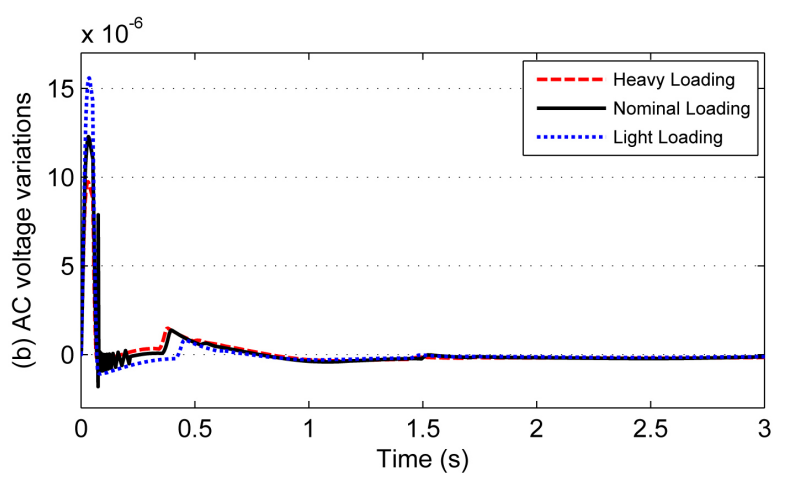

(b)

Fig. 12. System transient response for a three-cycles fault disturbance with nominal, light, and heavy loading in combined control scheme. (a) DC capacitor voltage variations and (b) AC voltage variations.

voltage variations are compared in Fig. 9 for the nominal operating point following a $3 \%$ disturbance in the mechanical generator power input for a three-cycle fault duration. It can be clearly seen that in the combined control scheme (with the inclusion of a FLC on a PSS and considering the optimal controller parameters of a STATCOM), the electromechanical damping characteristics of the system are improved. Also the $\mathrm{DC}$ capacitor voltage variations and the $\mathrm{AC}$ voltage variations are shown in Fig. 10. It can be observed that the combined control scheme gives a very good damping profile compared with using only a FLC-PSS individually.

To assess the effectiveness and robustness of the proposed combined controller, simulation studies are carried out for various operating conditions. The operating conditions considered are:

Case 1: Nominal loading: $P_{e}=0.8$ p.u. and $Q_{e}=0.28$ p.u.

Case 2: Heavy loading: $P_{e}=1$ p.u. and $Q_{e}=0.34$ p.u.

Case 3: Light loading: $P_{e}=0.6$ p.u. and $Q_{e}=0.26$ p.u.

Fig. 11 and 12 show the system dynamic response for a three-cycle fault disturbance for rotor speed variations, rotor angle variations, terminal voltage variations, internal voltage variations, DC capacitor voltage variations, and AC voltage variations in the combined control scheme. It can be observed that the combined control scheme gives a very good damping profile over a range of operating conditions.

Fig. 13 and 14 show the system dynamic response for a tripping line at $t=1$ for rotor speed variations and terminal voltage variations in uncombined and combined control schemes. To

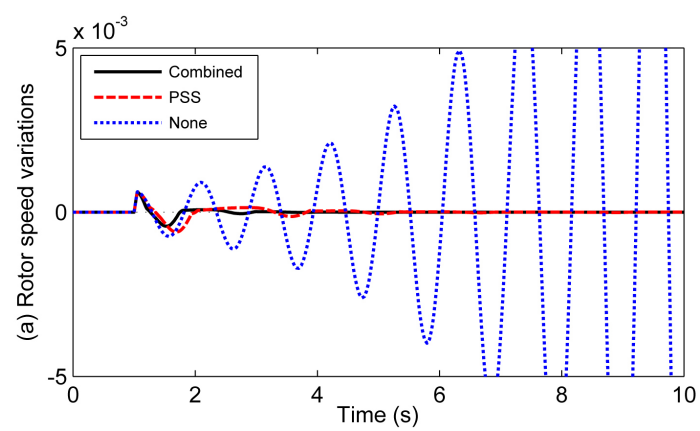

(a)

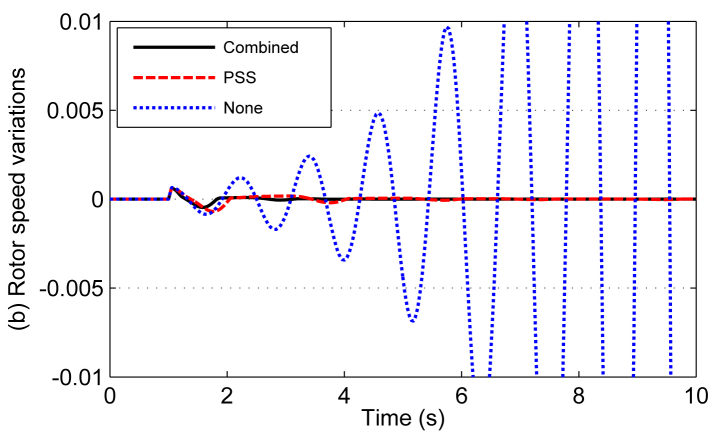

(b)

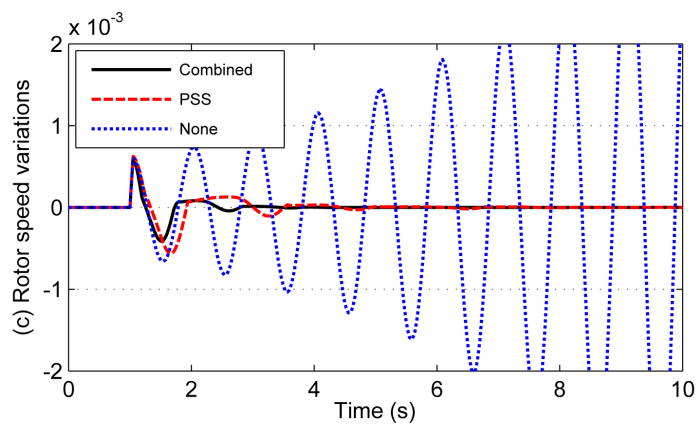

(c)

Fig. 13. System transient response of rotor speed variations for tripping line condition, (a) Normal loading, (b) Heavy loading, and (c) Light Loading.

demonstrate the robust performance of the proposed controller, three performance indices are defined as follows [35]:

$$
\begin{array}{r}
I T A E=100 \int_{0}^{t_{\text {sim }}} t \times\left[|d w|+\left|d v_{t}\right|+|d \delta|\right] d t \\
I T S E=1000 \int_{0}^{t_{\text {sim }}} t \times\left[(d w)^{2}+\left(d v_{t}\right)^{2}+(d \delta)^{2}\right] d t \\
F D=(1000 \times O S)^{2}+(4000 \times U S)^{2}+\left(T_{S}\right)^{2}
\end{array}
$$

where ITAE is the integral of the time multiplied absolute value of the error, ITSE is the integral of the time multiplied square of the error and FD is the figure of demerit.

The overshoot (OS), undershoot (US) and settling time of the speed deviation of the machine $\left(\mathrm{T}_{S}\right)$ are considered when calculating the FD. Table II shows the values of the performance indices for all of the considered cases. It is very important to mention that the lower values of these indices show better performance in the system. Corresponding to Table II, the outstanding performance of the combined based controller is clear. 
TABLE II

VALUES OF PERFORMANCE INDICES ITAE, ITSE, AND FD

\begin{tabular}{|c|c|c|c|c|c|c|c|c|c|c|}
\hline \multirow{4}{*}{$\begin{array}{l}\text { Without } \\
\text { tripping } \\
\text { line }\end{array}$} & \multirow[b]{2}{*}{ Controller } & \multicolumn{3}{|c|}{ Case 1 (Normal) } & \multicolumn{3}{|c|}{ Case 2 (Heavy) } & \multicolumn{3}{|c|}{ Case 3 (Light) } \\
\hline & & ITAE & ITSE & FD & ITAE & ITSE & FD & ITAE & ITSE & FD \\
\hline & Combined & 0.1793 & 0.0023 & 3.3908 & 2.6113 & 0.3853 & 15.5267 & 0.2725 & 0.0061 & 5.3242 \\
\hline & Uncombined & 4.3280 & 0.6640 & 18.69 & 6.023 & 1.017 & 21.441 & 4.6461 & 0.665 & 17.1665 \\
\hline \multirow{4}{*}{$\begin{array}{l}\text { With } \\
\text { tripping } \\
\text { line }\end{array}$} & Controller & \multicolumn{3}{|c|}{ Case 1 (Normal) } & \multicolumn{3}{|c|}{ Case 2 (Heavy) } & \multicolumn{3}{|c|}{ Case 3 (Light) } \\
\hline & Controller & ITAE & ITSE & FD & ITAE & ITSE & FD & ITAE & ITSE & FD \\
\hline & Combined & 2.0617 & 0.2 & 13.8730 & 2.4908 & 0.2918 & 18.0885 & 1.9268 & 0.2029 & 11.3049 \\
\hline & Uncombined & 8.6504 & 1.4932 & 30.2052 & 17.0073 & 3.8976 & 33.2366 & 6.3311 & 0.8990 & 21.1442 \\
\hline
\end{tabular}

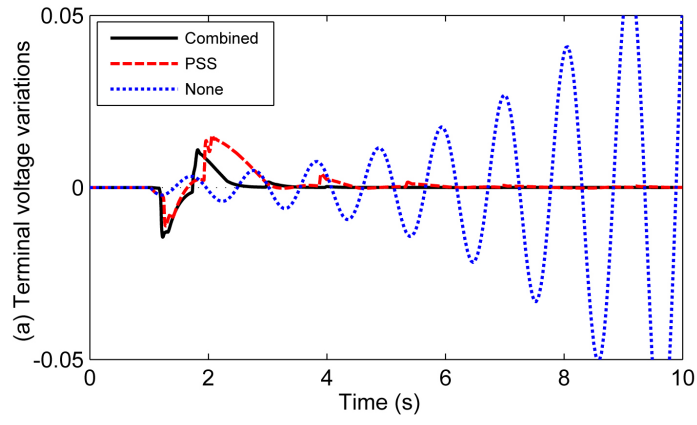

(a)

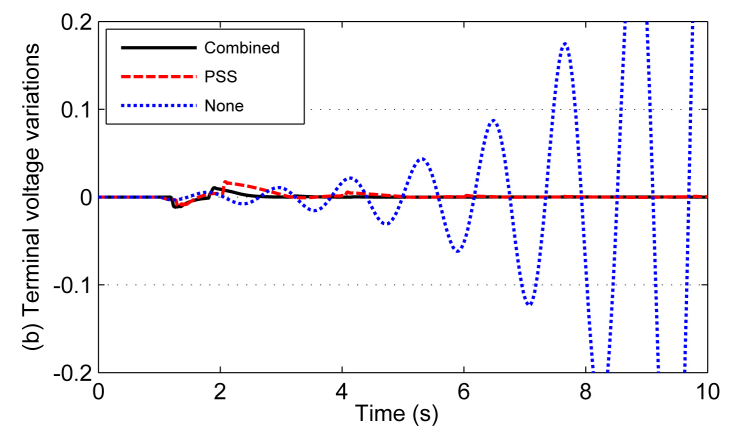

(b)

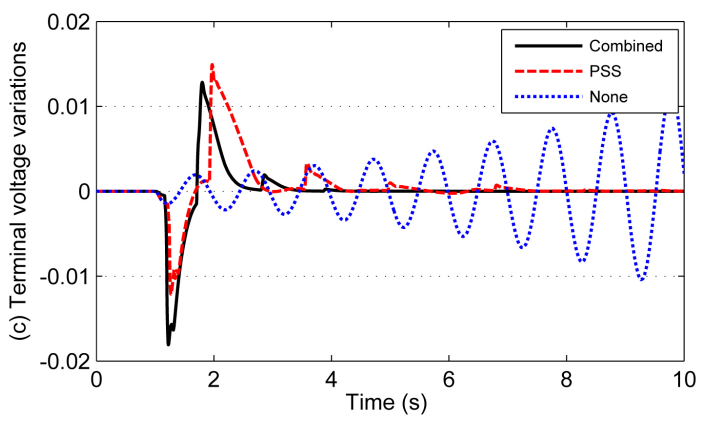

(c)

Fig. 14. System transient response of terminal voltage variations for tripping line condition. (a) Normal loading. (b) Heavy loading. and (c) Light Loading.

\section{CONCLUSION}

In this paper a combined design of a STATCOM and a power system stabilizer is used to power system stability enhancement. A fuzzy logic controller has designed for the PSS and particle swarm optimization is employed to search for the optimal STATCOM controller parameters in a SMIB system with a STATCOM located at the midpoint of the transmission line. The optimal design of the controllers has been implemented on a proposed system and discussed in three different schemes. The system performance characteristics demonstrate that the combined design of the STATCOM and PSS controllers is superior to the uncombined design of the controllers. The system performance characteristics in terms of the 'ITAE', 'ITSE' and 'FD' indices demonstrate the exceptional performance of the proposed controller.

\section{APPENDIX}

Parameters of the studied system (in per unit unless otherwise indicated)

SMIB and STATCOM parameter values

\begin{tabular}{|c|c|}
\hline Generator & $\begin{array}{l}M=4 M J / M V A ; T^{\prime}{ }^{\prime}=5.044 \mathrm{~s} ; D=0 ; \\
w_{b}=120 \pi \mathrm{rad} / \mathrm{s} ; X_{d}=1 ; X_{q}=0.6 ; X^{\prime}{ }_{d}=\end{array}$ \\
\hline $\begin{array}{l}\text { Excitation } \\
\text { System }\end{array}$ & $k_{A}=50 ; T_{A}=0.01$ \\
\hline Transformer & $X_{t}=0.5$ \\
\hline $\begin{array}{l}\text { Transmission } \\
\text { Lines }\end{array}$ & $X_{e 1}=0.3 ; R_{e 1}=0 ; X_{e 2}=0.6 ; R_{e 2}=0$ \\
\hline $\begin{array}{l}\text { STATCOM } \\
\text { Parameters }\end{array}$ & $V_{d c}=2 ; C_{d c}=1 ; T_{c}=0.01$ \\
\hline $\begin{array}{l}\text { Operating } \\
\text { Condition }\end{array}$ & $\begin{array}{l}V_{t}=1.05 ; V_{m}=1.0 ; V_{b}=1.0 \\
P_{e}=0.8 ; Q_{e}=0.28\end{array}$ \\
\hline
\end{tabular}

\section{REFERENCES}

[1] N. G. Hingoran and L. Gyugy, Understanding FACTS, Concepts and Technology of Flexible AC Transmission System, Wiley- IEEE press, 1 Ed., Dec. 1999.

[2] N.G. Hingorani, "High power electronics and flexible AC transmission system," IEEE Power Engineering review, Vol. 8, 1988.

[3] B.T. Ooi, M. Kazerani, R. Marceau, Z. Wolanski, F.D. Galiana, D. McGills, G. Joos, "Mid-point siting of FACTS devices in transmission lines," IEEE Trans. Power Del. Vol. 12 , No. 4, pp. 1717-1722, Oct. 1997.

[4] B. Singh, R. Saha, A. Chandra, and K. Al-Haddad, "Static synchronous compensators (STATCOM): a review," IET Power Electronics, Vol. 2, pp. 297-324, Jul. 2009.

[5] M. S. Nikunj, K. S. Vijay, and V. Ramachandran, "Modeling, control and simulation of a chain link STATCOM in EMTP-RV," Electric Power Systems Research, Vol. 79, pp. 474-483, 2009.

[6] N. C. Sahoo, B. K. Panigrahi, P. K. Dash, and G. Panda, "Application of a multivariable feedback linearization scheme for STATCOM control," Electric Power Systems Research, Vol. 62, pp. 81-91, 2002.

[7] A. H. M. A. Rahim, and M. F. Kandlawala, "Robust STATCOM voltage controller design using loop-shaping technique," Electric Power Systems Research, Vol. 68, pp. 61-74, 2004.

[8] H. F. Wang, "Interactions and multivariable design of STATCOM AC and DC voltage control," journal of Electrical Power and Energy Systems, Vol. 25, pp. 387-394, 2003.

[9] P. F. Puleston, S. A. González, and F. Valenciaga, "A STATCOM based variable structure control for power system oscillations damping," Electrical Power and Energy Systems, Vol. 29, pp. 241-250, 2007.

[10] M. A. Abido, "Analysis and assessment of STATCOM-based damping stabilizers for power system stability enhance- ment," Electric Power Systems Research, Vol. 73, pp. 177-185, 2005.

[11] M. S. El-Moursi, and A. M. Sharaf, "Novel reactive power controllers for the STATCOM and SSSC," Electric Power Systems Research, 76, pp. 228-241, 2006. 
[12] S. Krishna, "Stability analysis of Static Synchronous Compensator with reactive current controller," Electric Power Systems Research, Vol. 78, pp. 1053-1068, 2008.

[13] Y. S. Lee, and S. Y. Sun, "STATCOM controller design for power system stabilization with sub-optimal control and strip point assignment," Electric Power and Energy Systems, Vol. 24, pp. 771-779, 2002.

[14] S. A. AL-Baiyat, "Power system transient stability enhancement by STATCOM with nonlinear H stabilizer," Electric Power Systems Research, Vol. 73, pp. 45-52, 2005.

[15] N. C. Sahoo, B. K. Panigrahi, P.K. Dash, and G. Panda, "Multivariable nonlinear control of STATCOM for synchronous generator stabilization," Electrical Power and Energy Systems, Vol. 26, pp. 37-48, 2004.

[16] F. Liu, S. Mei, Q. Lu, Y. Ni, F.F. Wu, and A. Yokoyama, "The nonlinear internal control of STATCOM: theory and application," Electrical Power and Energy Systems, Vol. 25, pp. 421-430, 2003.

[17] G. T. Tse, and S. K. Tso, "Refinement of conventional PSS design in multimachine system by modal analysis," IEEE Trans. Power Syst., Vol. 8, No. 2, pp. 598-605, May 1993.

[18] P. Kundur, M. Klein, G.J. Rogers, and M.S. Zywno, "Application of power system stabilizers for enhancement of overall system stability," IEEE Trans. Power Syst., Vol. 4, No. 2, pp. 614-626, May 1989.

[19] S. Panda, and N. P. Padhy, "Optimal location and controller design of STATCOM for power system stability improvement using PSO," Journal of the Franklin Institute, Vol. 345, pp. 166-181, 2008.

[20] S. F. Faisal, A. H. M. A. Rahim, and J. M. Bakhashwain, "A robust statcom controller for a multimachine power system using particle swarm optimization and loop-shaping," International Journal of Electrical, Computer, and Systems Engineering, pp. 64-70, 2007.

[21] L. Zadeh, "Fuzzy sets", Information and Control, 8, 1965.

[22] A. H. M. A. Rahim, E. P. Nowicki, and J. M. Bakhashwain, "Fuzzy STATCOM Control Strategies for Power System Stabilization," ACSE Journal, Vol. 6, pp. 1-9, 2006.

[23] S. Morris, P.K. Dash, and K.P. Basu, "A fuzzy variable structure controller for STATCOM," Electric Power Systems Research, 65, pp. 23-34, 2003

[24] A. Luo, C. Tang, Z. Shuai, J. Tang, X.Y. Xu, and D. Chen, "Fuzzypi-based direct-output-voltage control strategy for the statcom used in utility distribution systems," IEEE Trans. Ind. Electron., Vol. 56, No. 7, pp. 2401-2411, Jul. 2009.

[25] L. Gu, and J. Wang, "Nonlinear coordinated control design of excitation and STATCOM of power systems," Electric Power Systems Research, Vol. 77, pp. 788-796, 2007.

[26] D. Z. Fang, S. Q. Yuan, Y. J. Wang and T. S. Chung, "Coordinated parameter design of STATCOM stabiliser and PSS using MSSA algorithm," IET Gener. Transm. Distrib., Vol. 1, No. 4, pp. 670-678, Jul. 2007.

[27] H. Shayeghi, S. Jalilizadeh, H. Shayanfar, and A. Safari, "Simultaneous Coordinated Designing of UPFC and PSS Output Feedback Controllers Using PSO," Journal of Electrical Engineering, Vol. 60, No. 4, pp. 177 184, 2009.

[28] P. Pourbeik and M .J. Gibbard, "Simultaneous coordination of powersystem stabilizers and FACTS device stabilizers in a multimachine power system for enhancing dynamic performance," IEEE Trans. Power Syst., Vol. 13, No. 2, pp. 473-479, May 1998.
[29] L. J. Cai and I. Erlich, "Simultaneous coordinated tuning of PSS and FACTS damping controllers in large power systems," IEEE Trans. Power Syst., Vol. 20, No. 1, pp. 294-300, Feb. 2005.

[30] X. Lei, E. N. Lerch, and D. Povh, "Optimization and coordination of damping controls for improving system dynamic performance," IEEE Trans. Power Syst., Vol. 16, No. 3, pp. 473-480, Aug. 2001.

[31] M. Joorabian, M. Razzaz, M. Ebadi, and M. Moghaddasian, "Employing fuzzy logic in damping power system oscillations using svc," IEEE International Conference on Electrical Engineering, pp. 1-5, Mar. 2008.

[32] H. N. Ng, M. M. A. Salama and A. Y. Chikhani, "Classification of capacitor allocation techniques," IEEE Trans. Power Del., Vol. 15, No. 1, pp. 387-392, Jan. 2000.

[33] H.A. Toliat, J. Sadeh and R. Ghazi, "Design of augmented fuzzy logic power system stabilizers to enhance power system stability," IEEE Trans. Energy Convers., Vol. 11, No. 1, pp. 97-103, Mar. 1996.

[34] J. Kennedy, and R.C. Eberhart, "Particle swarm optimization," IEEE International Conference on neural networks, Vol. 4, pp. 1942-1948, 1995.

[35] S. Panda and N. P. Padhy, "Comparison of particle swarm optimization and genetic algorithm for FACTS-based controller design," Applied Soft Computing, Vol. 8, pp. 1418-1427, 2008.

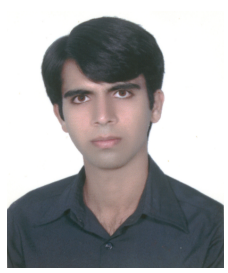

Ahmad Rohani was born in Shiraz, Iran, in 1984 $\mathrm{He}$ received his B.S. from I.A.U., Bushehr branch, Iran, in 2007, and his M.S. from Zanjan University, Iran, in 2010, both in Electrical Engineering. He is a Member of the Young Researchers Club (YRC), Shiraz branch, Iran. His research interests include renewable energies, control and stabilization of power systems, the application of intelligent methods in power systems, and network expansion planning.

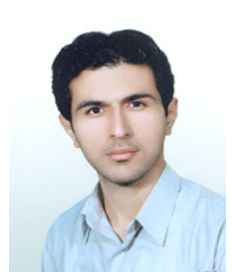

M. Reza Safari Tirtashi was born in Behshahr, Iran in 1986. He received his B.S. in Electrical Engineering from Mazandaran University, Iran, in 2008, and his M.S. in Electrical Engineering from Zanjan University, Iran, in 2011. He is a member of the Young Researchers Club (YRC), Behshahr branch, Iran. His research interests include the control and stabilization of power systems, the application of intelligent methods in power systems, wind energy conversion systems and HVDC light trans-

mission systems.

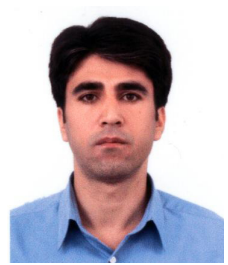

Reza Noroozian was born in Iran. He is an Assistant Professor in the Department of Power Engineering, University of Zanjan, Iran. He received his B.S. from Tabriz University, Tabriz, Iran, in 2000, his M.S. and Ph.D. in Electrical Engineering from the Amirkabir University of Technology (AUT), Iran, in 2003 and 2008, respectively. His research interests include power electronics, power systems, power quality, the integration and control of renewable generation units, custom power, micro-gric operation, distributed generation modeling, operation and interface control. 